Article

\title{
Dynamic Ecological Risk Assessment and Management of Land Use in the Middle Reaches of the Heihe River Based on Landscape Patterns and Spatial Statistics
}

\author{
Jiahui Fan ${ }^{1,2}$, Ya Wang ${ }^{1,2}$, Zhen Zhou ${ }^{1,2}$, Nanshan You ${ }^{1,2}$ and Jijun Meng ${ }^{1,2, *}$ \\ 1 College of Urban and Environmental Sciences, Peking University, Beijing 100871, China; \\ 18800120818@163.com (J.F.); wangyayas@sina.com (Y.W.); zhouzhen2014@126.com (Z.Z.); \\ nanshany@pku.edu.cn (N.Y.) \\ 2 Key Laboratory for Earth Surface Processes, Ministry of Education, Peking University, Beijing 100871, China \\ * Correspondence: jijunm@pku.edu.cn; Tel.: +86-10-6275-8503
}

Academic Editor: Vincenzo Torretta

Received: 14 March 2016; Accepted: 31 May 2016; Published: 6 June 2016

\begin{abstract}
Land use profoundly changes the terrestrial ecosystem and landscape patterns, and these changes reveal the extent and scope of the ecological influence of land use on the terrestrial ecosystem. The study area selected for this research was the middle reaches of the Heihe River. Based on land use data (1986, 2000, and 2014), we proposed an ecological risk index of land use by combining a landscape disturbance index with a landscape fragility index. An exponential model was selected to perform kriging interpolation, as well as spatial autocorrelations and semivariance analyses which could reveal the spatial aggregation patterns. The results indicated that the ecological risk of the middle reaches of the Heihe River was generally high, and higher in the northwest. The high values of the ecological risk index (ERI) tended to decrease, and the low ERI values tended to increase. Positive spatial autocorrelations and a prominent scale-dependence were observed among the ERI values. The main hot areas with High-High local autocorrelations were located in the north, and the cold areas with low-low local autocorrelations were primarily located in the middle corridor plain and Qilian Mountains. From 1986 to 2014, low and relatively low ecological risk areas decreased while relatively high risk areas expanded. A middle level of ecological risk was observed in Ganzhou and Minle counties. Shandan County presented a serious polarization, with high ecological risk areas observed in the north and low ecological risk areas observed in the southern Shandan horse farm. In order to lower the eco-risk and achieve the sustainability of land use, these results suggest policies to strictly control the oasis expansion and the occupation of farmland for urbanization. Some inefficient farmland should transform into grassland in appropriate cases.
\end{abstract}

Keywords: landscape pattern; ecological risk; spatial statistics; dynamic evaluation; Heihe River

\section{Introduction}

Human activities are currently causing profound changes to the terrestrial ecosystem, primarily through land use [1]. The eco-environmental effect of land use change has become the core content of research into global change [2,3]. In landscapes dominated by human activities, the land use reflects the manner and extent of human influence on the natural ecosystem. Ecological risk is a combination of likelihoods and consequences on ecosystems and their components caused by uncertain events or disasters [4-6]. With regional and cumulative characteristics, the influence of land use on ecosystems can directly reflect changes of ecosystem structure and components [7]. Therefore, ecological risk analysis based on land use and landscape structure can integrate evaluations 
of different potential ecological influences and their cumulative characteristics. With the development of studies on ecological risk management, the ecological risk caused by land use has become a focus of research because it is an important human disturbance risk [8-11].

In recent years, scholars have used different methods to measure the ecological risk of land use. Ecological risk indexes were established to assess ecological risk based on the land use structures and ecological risk intensity parameters $[8,12,13]$. Based on comprehensive index in ecological risk of LUCC, Yang, Sun, and Wang worked out that the mean ecological risk index in Shandong Province is 0.3 , which belongs to middle level of risk [14]. In other proposed approaches, the exposure and effects of the risk sources and receptors are characterized to assess ERI in relative risk models $[15,16]$. Bayliss, van Dam, and Bartolo combined both point-source mining risks and diffuse non-mining landscape-scale risks to show that non-mining landscape-scale risks were several orders of magnitude greater than risks from mine water contaminants in in Kakadu National Park, Australia [17]. In addition, landscape structure indexes have been applied to reflect the ecological risk levels of land use derived from ecosystem structures $[11,18]$. The degree of ecosystem loss must be determined by a landscape disturbance index $\left(E_{i}\right)$ and a landscape fragility index $\left(F_{i}\right)$ that include a crush index $\left(C_{i}\right)$, split index $\left(S_{i}\right)$, and dominance index $\left(D_{O i}\right)$, and then the degree of ecological risk can be described by the division of risk subareas. Due to the highly concentrated landscape pattern information, the landscape pattern index can be used to quantitatively express and describe changes of the structural characteristics of the landscape [19]. For gaps in the accumulated historical ecological monitoring information, ecological risk analyses based on landscape patterns can also integrate evaluations of potential types of ecological influences and their cumulative consequences [20]. In addition, the high autocorrelation of the landscape pattern along a certain direction may indicate that certain ecological processes play an important role [21]. Spatial statistical analyses of ecological risk that include land use can accurately demonstrate spatial distributions and change gradients characteristics for various ecological influences [20]. This paper focuses on the middle reaches of the Heihe River as the study area. Landscape ecology theories, spatial statistical analysis methods, and GIS technology were used to construct a land use ecological risk assessment model capable of revealing the spatial and temporal characteristics of ecological risk from land use. We aimed to provide new insights and methods related to regional sustainable land use and ecosystem management.

\section{Study Area}

The area of the middle reaches of the Heihe River, which is located in the western region of Gansu Province and the middle of the Hexi Corridor, is a central traffic artery. The administrative divisions of the study area include Ganzhou, Gaotai, Linze, Minle, and Shandan counties, and the Sunanminghua area of Sunan County, which account for a total area of 19,600 km² (Figure 1). The Qilian Mountains in the south present rugged terrain and lush vegetation, and represent an important water conservation area of the Hexi Corridor. The central oasis plain has rich soil and water resources, which makes it an important modern oasis agricultural base. The Heli Mountains and Longshou Mountains in the north are widely covered by desert and represent important barriers to sand and wind erosion. The area has a temperate continental climate with rare precipitation and abundant light hours. The study area is the main water consumption and more than $80 \%$ of the oasis, population, GDP, and cultivated land of the whole river basin are concentrated here. The agriculture industry is well developed in the area; however, the discrepancy between the supply and demand of water resources related to land use is severe. 


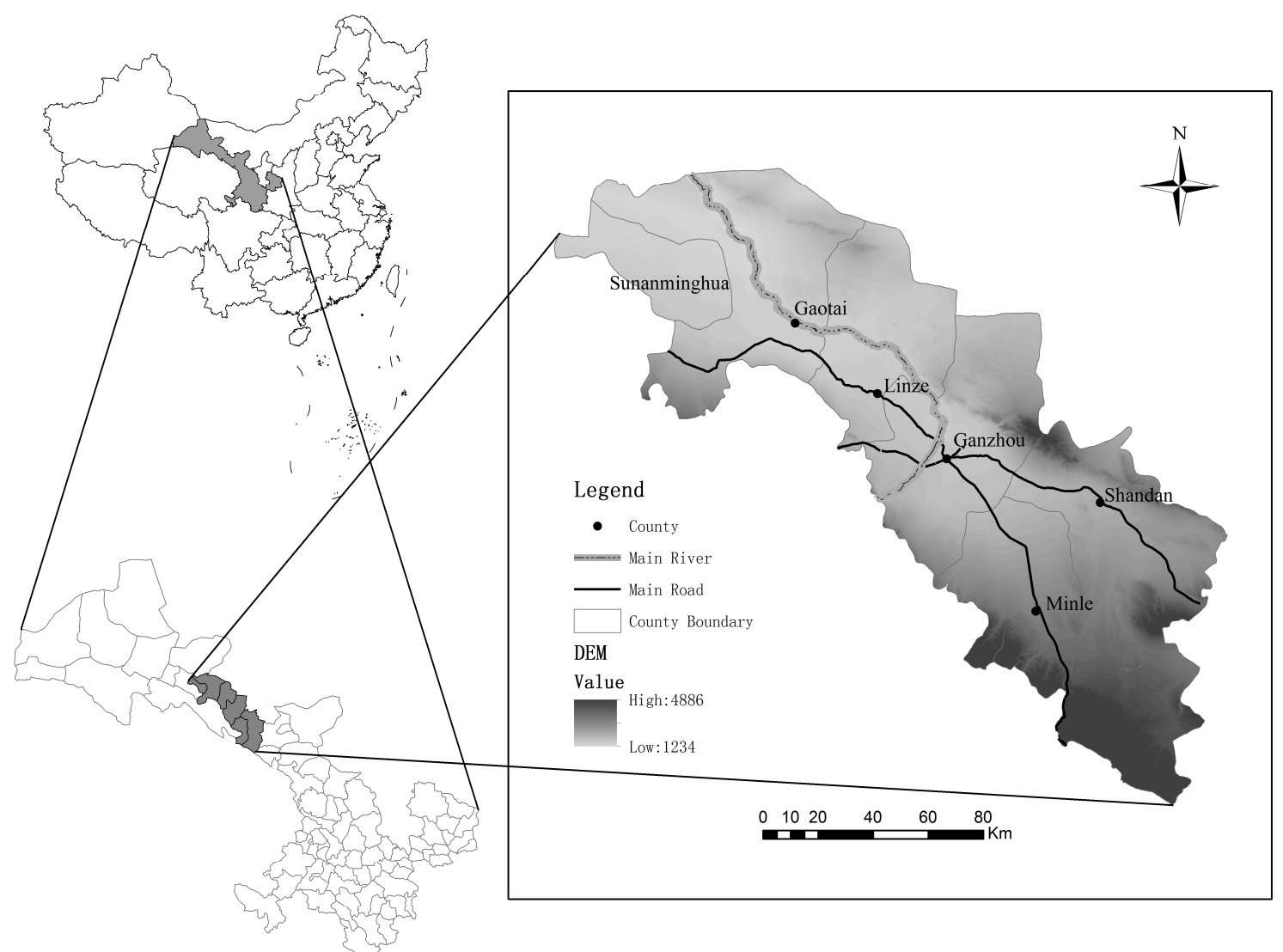

Figure 1. Location of the study area.

\section{Materials and Methods}

Combined with related research results on risk district divisions, a quantitative relationship between landscape metrics and ecological land use risk was constructed using a landscape disturbance index and landscape vulnerability index. The ecological land use risk metric was quantitatively analyzed based on spatial analyst functions and GIS statistics, and the landscape metrics were calculated by Fragstats 4.2 (Department of Forest Science of Oregon State University, Corvallis, OR, USA). Finally, spatial risk distribution maps were drawn, and the characteristics of the dynamic spatial-temporal changes of ecological risk were analyzed.

\subsection{Data Sources}

Land use data with a spatial resolution of $30 \mathrm{~m} \times 30 \mathrm{~m}$ from 1986, 2000, and 2014 were used in this research. The vector data from 1986 and 2000 were obtained from the "eight-five" project [22] of the Chinese Academy of Sciences and interpreted from Landsat TM and ETM remote sensing data, and the interpretation precision reached $93 \%$. The vector data from 2014 was interpreted from Landsat8 images downloaded from the USGS [23] using the human-computer interaction interpretation method based on ENVI4.7. The confusion matrix validation showed that the interpretation precision was $88.76 \%$. According to our research scope and the area's characteristics, the national land use classification method was used to divide the land uses in the study area into six types (resolution of $30 \mathrm{~m} \times 30 \mathrm{~m}$; Figure 2): farmland, forest, grassland, water, urban, and desert. The basic geographic data were obtained from the "Digital Heihe River" project [24], which is supported by the Cold and Arid Regions Sciences Data Center of the Chinese Academy of Sciences at Lanzhou [25]. The DEM data (30 $\mathrm{m} \times 30 \mathrm{~m}$ resolution) were derived from a global land cover database of the University of Maryland (USA). 


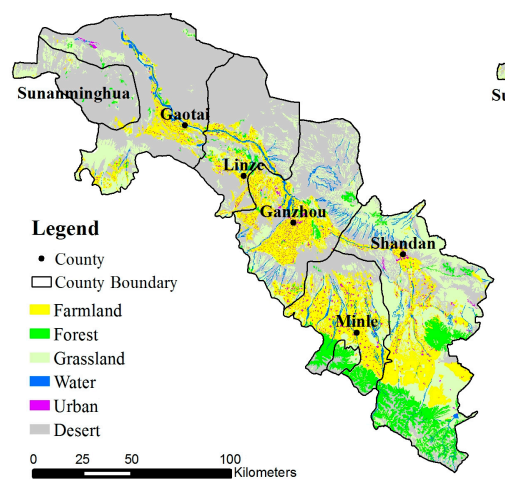

(a)

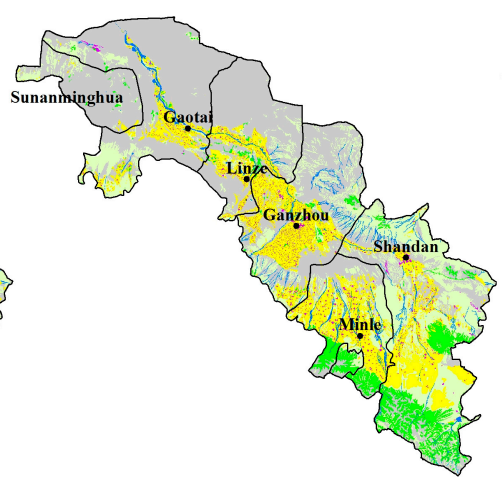

(b)

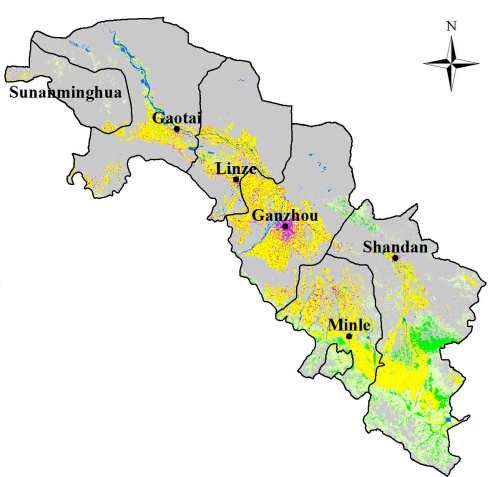

(c)

Figure 2. Land use maps of the middle reaches of the Heihe River in 1986 (a), 2000 (b), and 2014 (c).

\subsection{Risk District Division}

The division into risk districts is an important step for increasing the ecological risk index accuracy and the spatial visual expression of ecological risk. Landscape metrics change with scale (or size) $[21,26]$. Research was conducted to determine the changes in landscape metrics with spatial scale for different areas and topographies $[27,28]$. In this research, comprehensive comparisons between topography and slope based on the DEM showed that $5 \mathrm{~km} \times 5 \mathrm{~km}$ is a relatively ideal research scale. The study area was divided into 907 grids of $5 \mathrm{~km} \times 5 \mathrm{~km}$ based on the equidistance sampling function of ArcGIS 10.2 (Figure 3). Every grid was treated as a small risk district, and the ecological risks of these districts were calculated. Finally, the ecological risk of the center point of the grid, which is represented by the grid risk, was spatially interpolated.

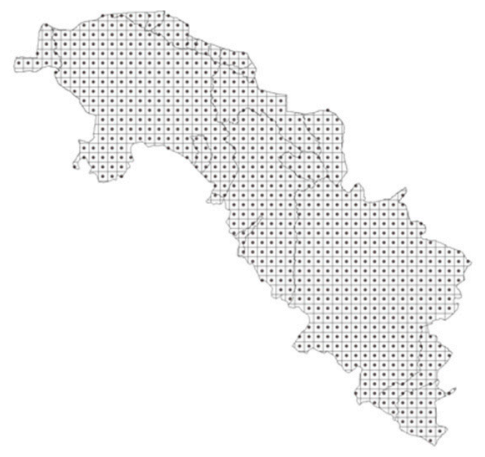

Figure 3. Unit of ecological risk assessment.

\subsection{Land Use Ecological Risk Structure}

\subsubsection{Landscape Disturbance Index (Ei)}

The landscape disturbance index reflects the degree of ecosystem interference in different landscapes [19] caused by hazards or land use activities. The landscape disturbance metric is usually obtained by superposition of several landscape metrics. In general, higher $E_{i}$ indicates higher ecological risk. Studies have used different landscape metrics, including the crush index $\left(C_{i}\right)$, split index $\left(S_{i}\right)$, and dominance index $\left(D_{O i}\right)[11,18]$. However, the complexity and connectivity among different ecosystems and the influence of human activity are not completely reflected in these indexes. Therefore, a perimeter-area fractal dimension index $\left(P_{i}\right)$, a normalized landscape shape index $\left(N_{i}\right)$, and a patch cohesion index $\left(J_{i}\right)$ were included here to fully reflect the landscape characteristics and the influence of human activity on the ecosystem. 
Among these metrics, the $C_{i}$, which is influenced by patch numbers, provides a representation of the patch crush degree and reflects the transition process of landscapes to complicated, idiosyncratic, discontinuous patch mosaics caused by natural or anthropogenic activities. The $S_{i}$ is determined by a distance and area index and reflects the separation degree of the distribution of different patches in one patch type. Higher $S_{i}$ values indicate more scattered and complicated landscape distributions and a higher degree of fragmentation. The $D_{O i}$ is determined by the frequency, density, and scale of patching, and it reflects the influence of patches on landscape pattern formation and change. The $P_{i}$ represents the complexity and stability of the landscape shape, and higher $P_{i}$ values indicate more irregular patch shapes and less human disturbance. The $N_{i}$ reflects the relative size of the patch edge under the same area conditions and represents the degree of complexity of the patch shape in the landscape. Higher $N_{i}$ values indicate more active material and energy exchanges between the patch and the external environment. The $J_{i}$ describes the patch cohesion degree, and higher $J_{i}$ values indicate higher patch integrity and fewer outside influences. The formula for the $E_{i}$ is as follows:

$$
E_{i}=\alpha C_{i}+\beta S_{i}+\chi D_{i o}+\delta P_{i}+\varphi N_{i}+\omega J_{i}
$$

where $\alpha, \beta, \chi, \delta, \varphi$, and $\omega$ represent the weight of the landscape metrics and $\alpha+\beta+\chi+\delta+\varphi+\omega=1$. $C_{i}, S_{i}, D_{\mathrm{O} i}, P_{i}, N_{i}$, and $J_{i}$ reflect the influence of land use processes on landscape disturbances to different degrees. $C_{i}$ and $S_{i}$ reflect partial characteristics; $P_{i}$ and $N_{i}$ reflect shape characteristics; $J_{i}$ reflects landscape integrity; and $D_{O i}$ reflects the landscape importance. The weights of $C_{i}, S_{i}, D_{O i}$, $P_{i}, N_{i}$, and $J_{i}(0.3,0.1,0.2,0.1,0.1$, and 0.2 , respectively) were determined according to the results of related research [29-31] and confirmed based on a tradeoff analysis.

\subsubsection{Landscape Fragility Index $\left(F_{i}\right)$}

The landscape fragility index represents the internal vulnerability of ecosystem structures within different landscapes and reflects the landscape's ability to resist outside interference. Lower resistance ability correlates to a higher fragility index and larger ecological risk [11]. Resistance ability is also related to the land use degree and varies among different landscape types [20]. In general, urban landscapes have the strongest resistance ability, while desert landscapes are the most vulnerable. The vulnerability of the six landscapes was determined according to previous research [32], and the order from high vulnerability to low was desert, water, cultivated land, grassland, forest, and urban, and the normalized $F i$ values were $0.286,0.238,0.190,0.143,0.095$, and 0.048 , respectively.

\subsubsection{Landscape Ecological Loss Degree (R)}

The ecological landscape loss degree is the measure and representation of ecosystem loss caused by outside interference (mainly human activity) [19]. The formula for $R_{i}$ is as follows:

$$
R_{i}=E_{i} \times F_{i}
$$

where $R_{i}$ is the ecological loss degree of landscape $i, E_{i}$ is the landscape disturbance index of landscape $i$, and $F_{i}$ is the landscape fragility index of landscape $i$.

\subsubsection{Ecological Risk Index of Land Use (ERI)}

Landscape metrics can influence on ecological risk to different degrees, and different landscapes present varying abilities to resist disturbance. The ERI was built to reflect the relationship between landscape metrics and regional ecological risk [33]. The ecological risk degree is determined through a comprehensive evaluation of the landscape fragility index for different landscapes in the study area. The formula of the ERI is as follows [34]:

$$
E R I=\sum_{i=1}^{n} \frac{A_{k i}}{A_{k}} R_{i}
$$


where $A_{k i}$ is the area of landscape $i$ in the $k$ sample area; $A_{k}$ is the total area of sample $k$; $R_{i}$ is ecological landscape loss degree; and $n$ is the number of landscape types.

\subsection{Spatial Statistical Analysis}

\subsubsection{Spatial Autocorrelation Analysis}

Spatial autocorrelation analyses can determine whether a correlation relationship occurs between elements at a specific spatial location and those at adjacent spatial locations [35]. By describing and visualizing the object or phenomenon's spatial distribution pattern, the fragmented and abnormal areas are identified, and the spatial interaction mechanisms between research objects can be revealed. Spatial autocorrelation analyses include two parts: global and local spatial autocorrelations. Global spatial autocorrelations describe an attribute's spatial characteristics throughout the entire subject area, and Moran's index is generally used to analyze the overall spatial correlation and difference degree.

Local spatial autocorrelations measured by Local Moran's I (LISA) can reveal the spatial heterogeneity of geographic phenomena or attribute values in a small local unit, and estimate the spatial location and scope of grouping areas.

The following results can be produced: High-High indicates that increases in the evaluated area increases the adjacent area value; High-Low indicates that increases in the evaluated area reduce the adjacent area value; Low-High indicates that decreases in the evaluated area increase the adjacent area value; and Low-Low indicates that decreases in the evaluated area decrease the adjacent area value [36].

\subsubsection{Semivariance Analysis}

The semivariance (semivariation) function is the most widely used spatial correlation analysis tool in spatial statistics. This function can describe structural variations, as well as random variations, and it is a key function for regional variable spatial variation research. The semivariance function plays an important role in research related to the spatial distribution of geographic phenomena because it can provide associations among spatially-independent variables between samples [37].

Semivariance function graphs can be fitted by curve equations (theoretical models), including spherical models, Gaussian models, exponential models, etc. Based on the geostatistical analyst function of GIS, we calculated the experimental semivariance function and fit this function using the theoretical semivariance function. In general, an optimal model meets the following criteria: mean standardized close to 0 , minimum root mean square error, average mean error close to the root mean square error, and root mean square standardized close to 1 [38].

The degree of spatial heterogeneity of an ecological risk can be determined by the most optimal model. The spatial heterogeneity parameters mainly include the nugget (Co), partial sill (C), and range (a). The Co value is the regional variable variance and represents the spatial heterogeneity of the random parts, with higher nugget values indicating that a process occurring at a small scale cannot be ignored. The $C$ value represents the overall change caused by regional macro-factors, which is referred to as constitutive change. The range (a) value is the effective range scope of the regional variable autocorrelation; in general, the variables are considered to have an autocorrelation relationship within the scope and lack an autocorrelation relationship outside of the scope. The sill $(\mathrm{Co}+\mathrm{C})$ is the sum of the $C o$ and $C$ and represents the overall change of regional variables. The $C / C o+C$ value represents the influence degree of random factors on the overall spatial change of regional variables, and higher $\mathrm{C} / \mathrm{Co}+\mathrm{C}$ valued indicate that the spatial change of regional variables caused by random factors was dominant, whereas lower $\mathrm{C} / \mathrm{Co}+\mathrm{C}$ values indicate that the spatial change of regional variables caused by structural factors was dominant. 


\section{Results}

\subsection{Temporal and Spatial Dynamic Characteristics of the Ecological Risk Index}

The spatial distributions of the ERI in 1986, 2000, and 2014 are illustrated in Figure 4. It showed the relative risk in the north-west is much higher than in the southeast and the bank of Heihe River. The average ERI values of these three periods were 4.54,4.44, and 5.03, respectively, and the maximum ERI values were $6.45,6.45$, and 6.89 , respectively. The ecological risk of the middle reaches of the Heihe River was generally high, and the ERI was stable from 1986 to 2000, but increased considerably after 2000. The ERIs of 352 grids (representing $38.76 \%$ of the total grids) primarily located in the northwest, which has a relatively high ecological risk level, were reduced. The indexes of 556 grids primarily located in the Qilian Mountains and northeastern regions showed significant improvements, which was related to the degeneration of grasslands and decreases in the vegetation fraction. Overall, the ecological risk in the middle reaches of the Heihe River was some high and has been increased over the past 14 years. The trend of ERI values in the middle reaches of the Heihe River showed reductions in high values and increases in low values. The scope of high value extended from the north-west to the middle plain and the low value area scaled back.

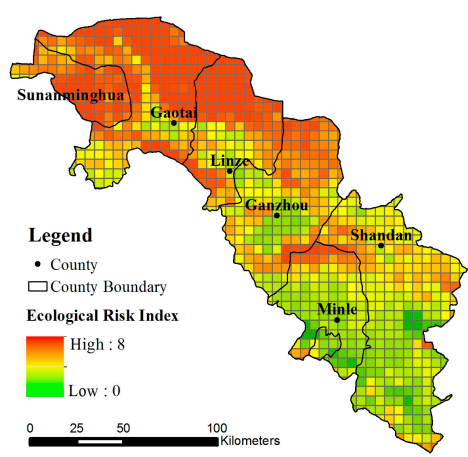

(a)

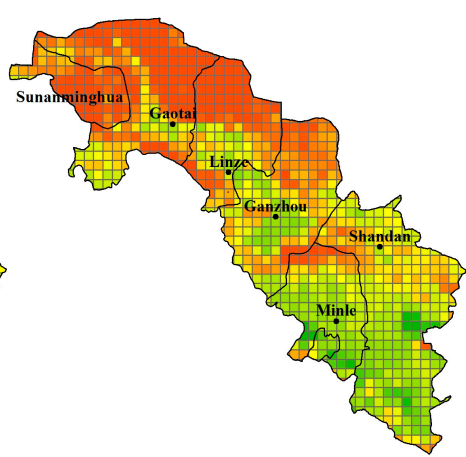

(b)

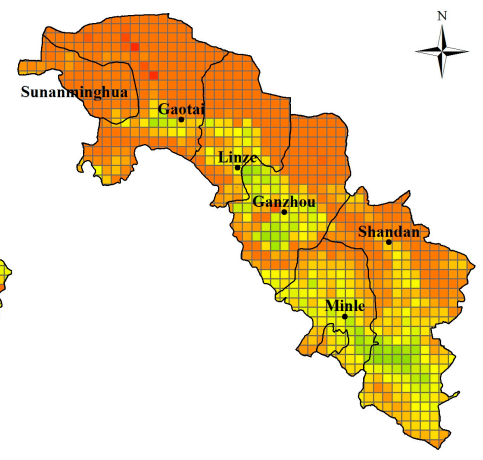

(c)

Figure 4. Ecological risk index maps of the middle reaches of the Heihe River in 1986 (a), 2000 (b), and 2014 (c).

\subsection{Global Moran's I of the Ecological Risk Index}

In landscape ecology, scale is often expressed according to the grain and extent [39]. For spatial data and remote sensing imagery, grain indicates the maximum resolution or pixel size. Analyses of Moran's I's are responsive to grain (Table 1), which makes it possible to interpret the spatial autocorrelation features of the ERI.

Table 1. Moran's I value for the ecological risk index in the middle reaches of the Heihe River under different granularities.

\begin{tabular}{cccc}
\hline \multirow{3}{*}{ Grain/m } & \multicolumn{3}{c}{ Moran's I } \\
\cline { 2 - 4 } & $\mathbf{1 9 8 6}$ & $\mathbf{2 0 0 0}$ & $\mathbf{2 0 1 4}$ \\
\hline $5 \mathrm{~km}$ & 0.82 & 0.82 & 0.77 \\
$20 \mathrm{~km}$ & 0.67 & 0.67 & 0.62 \\
$35 \mathrm{~km}$ & 0.58 & 0.58 & 0.49 \\
$50 \mathrm{~km}$ & 0.52 & 0.52 & 0.40 \\
$65 \mathrm{~km}$ & 0.48 & 0.48 & 0.34 \\
$80 \mathrm{~km}$ & 0.45 & 0.44 & 0.31 \\
$95 \mathrm{~km}$ & 0.42 & 0.42 & 0.29 \\
$110 \mathrm{~km}$ & 0.40 & 0.40 & 0.27 \\
$125 \mathrm{~km}$ & 0.38 & 0.38 & 0.26 \\
$140 \mathrm{~km}$ & 0.36 & 0.36 & 0.25 \\
\hline
\end{tabular}


According to Table 1, all of the Moran's I values were greater than zero under the different grain levels. Under the $5 \mathrm{~km}$ grain, the Moran's I values in 1986, 2000, and 2014 were $0.82,0.82$, and 0.77 , respectively, which indicated that positive spatial autocorrelations occurred among the ERIs. Moreover, three periods of autocorrelation tended to decrease without exception along with increases of grain. All of these results showed that prominent scale dependence occurred in the ERI spatial distribution. For the same grain level, the Moran's I value was relatively small in 2014 compared with that in 1986 and 2000. Thus, the global spatial autocorrelations in the study area only presented slight changes from 1986 until they began to decrease after 2000.

\subsection{Local Moran's I of the Ecological Risk Index}

According to the local Moran's I of the ERI for 907 grids in the study area (Figure 5), there were only three types of autocorrelations: "High-High" (HH), "Low-Low" (LL), and "not significant" (NS). Therefore, the local spatial autocorrelations of the ERI were high and lower indexes did not occur within the range of the region with high ERIs. Hot areas were mainly located in the north where the ecological environment is poor and presents vast desert areas and deficient vegetation. The high degree of ERI in this region and the adjoining area indicated a negative interaction with an increased likelihood of ecological risk. Conversely, colder areas presented considerably different scenarios. Most of these areas occur in the middle corridor plain and the Qilian Mountains, and they present considerable vegetation coverage and relatively low ecologic risks, which indicates a positive interaction with a decreased likelihood of ecological risk. The local Moran's I of the ERI only showed slight changes from 1986 to 2000 . However, the hot areas increased and cold areas decreased from 2000 to 2014, especially in the middle corridor plain, where the extension of "LL" was significant. Efforts to reduce the ecological risk of cold areas would benefit from decreasing the ERI in adjacent areas.

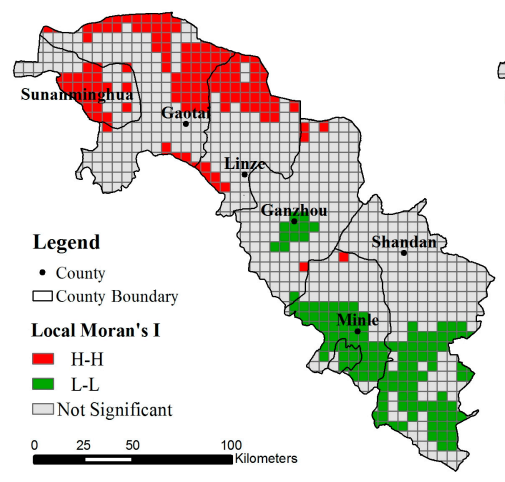

(a)

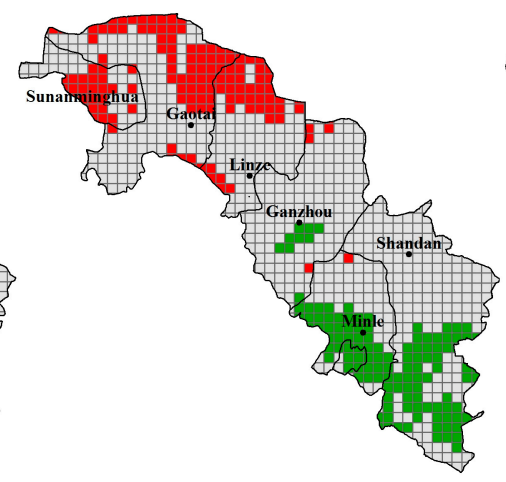

(b)

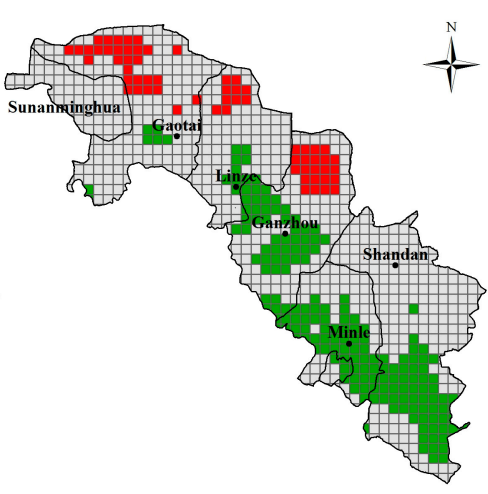

(c)

Figure 5. Local spatial autocorrelations of the ecological risk index in the middle reaches of the Heihe River in 1986 (a), 2000 (b), and 2014 (c).

\subsection{Spatial Fitting of the Ecological Risk Index}

The data analysis based on the geostatistical analyst function of ArcGIS indicated that the ERI of these three periods cannot coincide with, or be transformed to, a normal distribution. Disjunctive kriging was chosen to conduct the spatial fitting [40]. Based on the forecast error of the ERI (Table 2) and the standards of the optimal model, the exponential model was selected as optimal among these four models (Circular, Spherical, Exponential, Gaussian). The error value of the RMS was minimal, and the AME was closest to the RMSE. Moreover, the error value of the RMS was closest to 1 . Therefore, we selected the exponential model for the spatial interpolation and then obtained the statistics of the ecological risk semivariogram (Table 3). 
Table 2. Statistics of the prediction errors in four models in 1986, 2000, and 2014.

\begin{tabular}{cccccc}
\hline Year & Index & Circular & Spherical & Exponential & Gaussian \\
\hline \multirow{4}{*}{1986} & Mean Standardized & 0.0095 & 0.0108 & 0.0131 & 0.0014 \\
& Root Mean Square & 0.7065 & 0.6961 & 0.6197 & 0.7840 \\
& Average Mean Error & 0.8481 & 0.8346 & 0.7062 & 0.9543 \\
& Root-Mean-Square Standardized & 0.8315 & 0.8325 & 0.8749 & 0.8205 \\
\hline \multirow{2}{*}{2000} & Mean Standardized & 0.0100 & 0.0112 & 0.0132 & 0.0024 \\
& Root Mean Square & 0.7244 & 0.7139 & 0.6359 & 0.8022 \\
& Average Mean Error & 0.8790 & 0.8656 & 0.7354 & 0.9846 \\
& Root-Mean-Square Standardized & 0.8226 & 0.8231 & 0.8621 & 0.8137 \\
\hline \multirow{2}{*}{2014} & Mean Standardized & 0.0001 & 0.0004 & -0.0014 & 0.0031 \\
& Root Mean Square & 0.4846 & 0.4768 & 0.4103 & 0.4905 \\
& Average Mean Error & 0.7040 & 0.6889 & 0.5752 & 0.6651 \\
& Root-Mean-Square Standardized & 0.6889 & 0.6927 & 0.7128 & 0.7387 \\
\hline
\end{tabular}

Table 3. Statistics of the ecological risk semivariogram in 1986, 2000, and 2014 in the middle reaches of the Heihe River.

\begin{tabular}{cccccc}
\hline Year & Sill & Range & Nugget & Partial Sill & Nugget/Sill \\
\hline 1986 & 1.0498 & 171.0805 & 0.1073 & 0.9425 & $10.22 \%$ \\
2000 & 1.0488 & 171.0805 & 0.1133 & 0.9355 & $10.80 \%$ \\
2014 & 0.9685 & 84.3180 & 0.1951 & 0.7733 & $20.15 \%$ \\
\hline
\end{tabular}

A gradual decline of the partial sill from 1986 to 2014 indicated a gradual reduction in the inhomogeneity and variation of the ERI in the middle reaches of the Heihe River. The range presented a downtrend of approximately $170 \mathrm{~km}$ prior 2000 and narrowed to $84 \mathrm{~km}$ in 2014, which was caused by mutual transformation of land uses. The ecological risk situation in certain local areas was considerably different from the surrounding areas that a wide range of the original mean area was damaged and several types of land uses were fragmented. The nugget and partial sill rates were approximately $10 \%$ in 1986 and 2000 but increased to $20 \%$ in 2014, which indicated that random factors leading to sample variation had increased.

\subsection{Spatial Interpolation of the Ecological Risk Index}

The ecological risk maps of the middle reaches of the Heihe River in 1986, 2000, and 2014 were drawn by kriging interpolation. The degree of ecological risk was classified using ArcGIS into very low risk (0.7915-2.8567), low risk (2.8567-3.7671), medium risk (3.7617-4.7442), high risk (4.7442-5.7434), and very high risk (5.7434-6.8940) (Figure 6). The area proportion and landscape composition of these five risk types are shown in Figure 7. In terms of quantitative structure, the area of the five types of ecological risk presented limited changes from 1986 to 2000. The very low, low, medium, and high risk types accounted for approximately $20 \%$ of the total area, and the very high risk region accounted for $27 \%$. In 2014, the area of low and very low risk regions decreased significantly, especially the proportion of very low risk, which was less than $1 \%$, whereas the medium and high risk regions presented significant increases, with the area of high risk accounting for more than $40 \%$ of the entire area. In addition, the proportion of very high risk areas remained stable, which indicated that many low and very low ecological risk regions transformed into high and very high regions. In terms of spatial distribution and landscape composition, the spatial distribution of ecological risk in 1986 was similar to that in 2000 . The very high risk regions (96.25\% desert) were mainly located in the northwest and at the junction of Minle, Shandan, and Ganzhou counties. Most of the high ecological risk regions were located to the north of the Ganzhou County, and the periphery of this region included areas with very high risk. Moreover, $23.54 \%$ of this region presented a low coverage of grassland, although the dominant landscape was still desert. Ninety percent of the very low ecological risk regions consisted 
of farmland, forest, and pasture that were primarily located in the southern mountain area and oases along the main stream of the Heihe River. The spatial distribution of ecological risk showed considerable changes in 2014. The level of risk in the west decreased while the low risk regions in the northeast and Qilian Mountains improved significantly because of grassland degeneration and vegetation loss. The low and very low risk regions were only observed in the piedmont area of the Qilian Mountains and along the shore of the Heihe River. In conclusion, most of the high and very high risk regions were desert and low-covered grassland, while low and very low risk regions were forest and high-covered grassland. From 1986 to 2014, the area of high risk region has increased significantly, especially in the southeast and the middle plain.

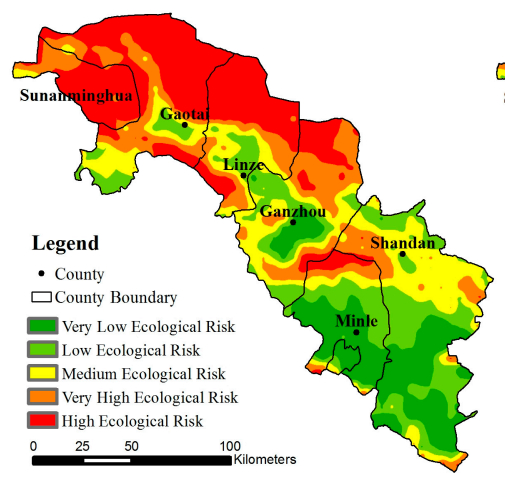

(a)

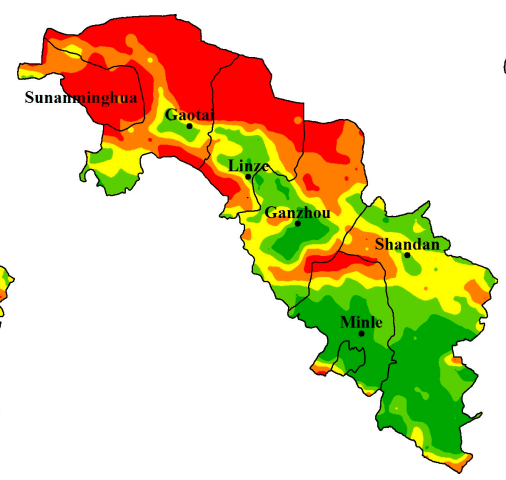

(b)

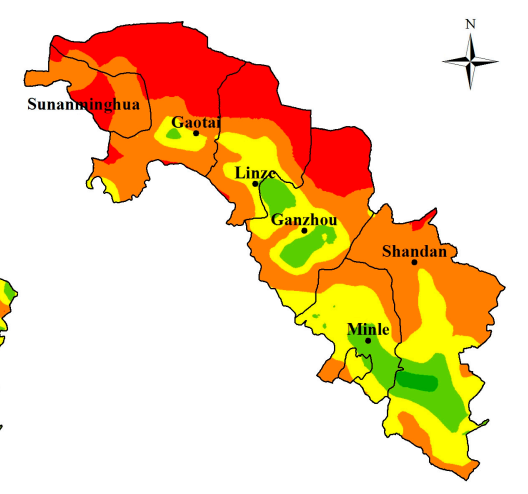

(c)

Figure 6. Ecological risk maps of the middle reaches of the Heihe River in 1986 (a), 2000 (b), and 2014 (c).

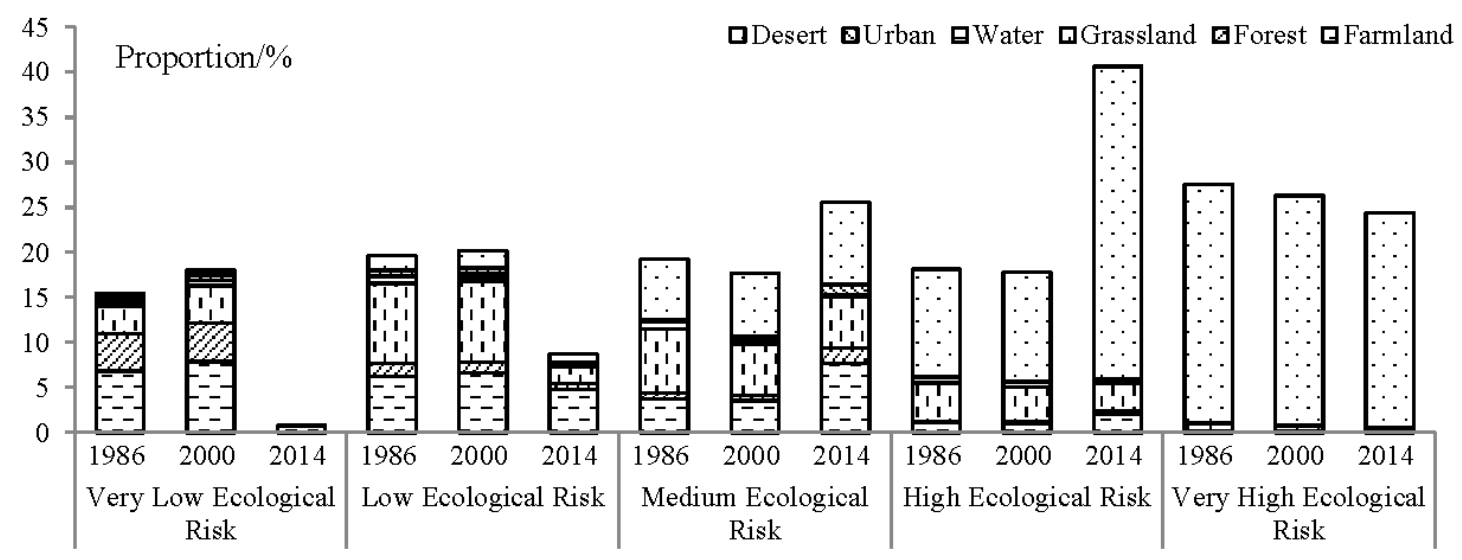

Figure 7. Acreage and landscape composition of the five different ecological risk regions.

According to the ecological risk statistics in different districts in the middle reaches of the Heihe River (Figure 8), the Gaotai, Linze, and Sunanminghua districts were the key districts where the ecological risk was relatively high and presented a significant declining trend, the Ganzhou and Minle disricts presented a mediocre degree, and the Shandan district presented a serious polarization. More than half of the Gaotai, Linze, and Sunanminghua district belonged to the very high ecological risk region from 1986 to 2000, although these percentages declined in 2014. In Sunanminghua, the proportion of the very high risk region decreased to $28.67 \%$ along with remarkable improvements to the ecological environment. Most of the low and very low ecological risk regions in Ganzhou showed slight increases; however, almost all of the very low risk region, which previously accounted for $50 \%$ of the Ganzhou district, had transformed to the medium risk level, and such increases in ecological risk should receive the appropriate amount of attention. Due to the fragile eco-environment in the 
north of Shandan district, more than half of the district, all of the medium and low ecological risk regions had transformed to high risk regions. However, the conditions were considerably different in Shandan district in the southern region, especially in the Shandan horse farm, which was the only very low ecological risk region and accounted for $154 \mathrm{~km}^{2}$ of the study area in 2014 .

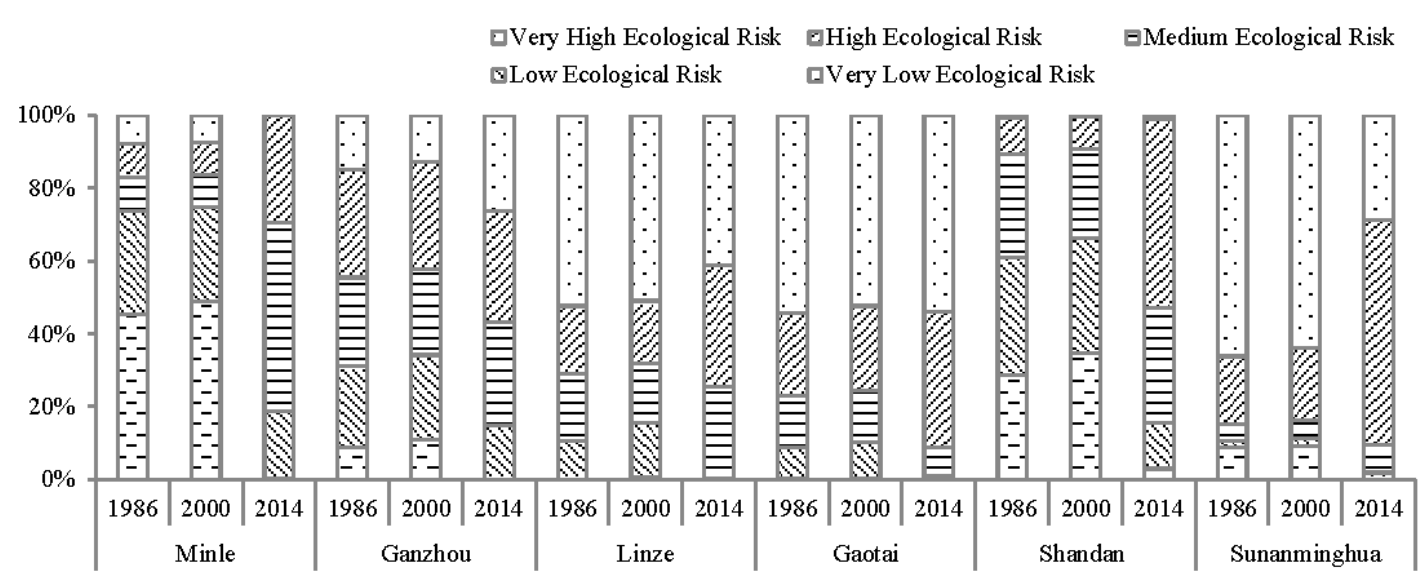

Figure 8. Statistics of ecological risk in the different counties in the middle reaches of the Heihe River.

The middle reaches of the Heihe River are important ecological security barriers for the Hexi Corridor. Zhangye is a tourism center in China, as well as the national demonstration pilot city for agricultural reform and construction, the national demonstration pilot city for ecological civilization, and the first national demonstration pilot city for water-ecological civilization, and it has continuously emphasized ecological environmental construction by controlling the expansion of the oasis and supporting the development of water-saving agriculture and ecological tourism. Due to the comprehensive advances obtained through the construction of an ecological city, local regions have shown reduced ecological risks and high risk areas have obviously decreased; however, the overall ecological risk of the entire region has increased, which is closely related to LUCC transformations (Table 4) and increased landscape fragmentation (Table 5). The land use changed smoothly from 1986 to 2000, but farmland and urban expansion is relatively remarkable. The increase of farmland is mainly derived from grassland reclamation, and the expansion of urban areas comes mainly from the occupation of farmland. Along with urban sprawl, the area of built-up land has nearly doubled since 2000 by extending into the surrounding farmland. Although certain low-yield fields were returned to forest and pasture, many forest and grassland areas were also transformed into desert, which was responsible for the 50\% decrease in grassland and 34\% increase in desert accounting for up to $12,344.27 \mathrm{~km}^{2}$ and $63 \%$ of the total area in 2014 . Due to the loss of natural forest and the degeneration of grassland caused by land use changes, ecological vulnerability has worsened, thereby increasing the degree of ecological risk. In addition, improvements to infrastructure, such as roads and ditches, have increased the level of human disturbance and landscape fragmentation. In 2014, the total number of patches (NP) skyrocketed to 52,306 from approximately 6000 in 1986 and 2000. Urban, forest, and grassland areas presented the most serious landscape fragmentation, especially urban areas, which presented a $C_{i}$ value of 0.2176 in 2014. The $C_{i}$ of all landscape types presented increases in 2014, particularly for forest and water, which increased to 0.1 from 0.004 . The $S_{i}$ presented similar variation trends as the $C_{i}$, and increases of the NP, $C_{i}$, and $S_{i}$ improved the $E_{i}$, which directly promoted the ecological risk. 
Table 4. Transfer matrix of land use change in the middle reaches of the Heihe River from 1986 to 2014.

\begin{tabular}{ccccccccc}
\hline & Farmland & Forest & Grassland & Water & Urban & Desert & Sum \\
\hline \multirow{5}{*}{$1986-2000$} & Farmland & 3475.62 & 0.00 & 37.17 & 0.84 & 14.38 & 0.37 & 3528.40 \\
& Forest & 7.73 & 1213.13 & 14.35 & 0.06 & 0.00 & 2.77 & 1238.05 \\
& Grassland & 202.80 & 5.40 & 4509.97 & 2.07 & 0.68 & 13.33 & 4734.25 \\
& Water & 39.79 & 0.00 & 0.11 & 506.85 & 0.03 & 0.20 & 546.98 \\
& Urban & 0.00 & 0.00 & 0.00 & 0.00 & 306.03 & 0.00 & 306.03 \\
& Desert & 22.28 & 1.03 & 1.30 & 1.03 & 0.26 & 9196.84 & 9222.74 \\
& Sum & 3748.23 & 1219.6 & 4562.90 & 510.85 & 321.38 & 9213.52 & $19,576.42$ \\
\hline \multirow{5}{*}{$2000-2014$} & Farmland & 2652.45 & 118.05 & 249.24 & 14.12 & 332.10 & 382.15 & 3748.11 \\
& Forest & 41.59 & 317.60 & 565.51 & 1.23 & 10.78 & 282.60 & 1219.31 \\
& Grassland & 281.42 & 291.71 & 1122.30 & 16.18 & 43.76 & 2806.58 & 4561.95 \\
& Water & 36.47 & 28.06 & 64.75 & 107.08 & 9.51 & 264.89 & 510.76 \\
& Urban & 87.13 & 2.91 & 16.53 & 3.68 & 155.08 & 56.04 & 321.36 \\
& Desert & 257.48 & 37.23 & 231.6 & 48.11 & 86.12 & 8552.02 & 9212.56 \\
& Sum & 3356.53 & 795.56 & 2249.93 & 190.40 & 637.35 & $12,344.27$ & $19,574.1$ \\
\hline
\end{tabular}

Table 5. Landscape pattern indexes of the middle reaches of the Heihe River in 2000 and 2014.

\begin{tabular}{ccccccccc}
\hline Time & Land Use Type & $\mathbf{N P}$ & $\boldsymbol{P}_{\boldsymbol{i}}$ & $\boldsymbol{J}_{\boldsymbol{i}}$ & $\boldsymbol{N}_{\boldsymbol{i}}$ & $\boldsymbol{C}_{\boldsymbol{i}}$ & $\boldsymbol{S}_{\boldsymbol{i}}$ & $\boldsymbol{D}_{\boldsymbol{O} \boldsymbol{i}}$ \\
\hline \multirow{6}{*}{2000} & Farmland & 840 & 1.4228 & 99.7661 & 0.0334 & 0.0022 & 0.0541 & 0.2741 \\
& Forest & 434 & 1.4310 & 99.4695 & 0.0380 & 0.0036 & 0.1195 & 0.1627 \\
& Grassland & 1485 & 1.4179 & 99.5555 & 0.0351 & 0.0033 & 0.0591 & 0.4242 \\
& Water & 218 & 1.7091 & 99.1523 & 0.0833 & 0.0043 & 0.2022 & 0.1564 \\
& Urban & 2775 & 1.3584 & 93.6813 & 0.1182 & 0.0863 & 1.1467 & 0.2872 \\
& Desert & 356 & 1.4432 & 99.9152 & 0.0144 & 0.0004 & 0.0143 & 0.4472 \\
\hline \multirow{4}{*}{2014} & Farmland & 4523 & 1.2674 & 99.7472 & 0.0434 & 0.0135 & 0.1402 & 0.2527 \\
& Forest & 8101 & 1.3004 & 98.8745 & 0.0875 & 0.1018 & 0.7915 & 0.2261 \\
& Grassland & 13,790 & 1.2708 & 99.4858 & 0.0679 & 0.0613 & 0.3651 & 0.3064 \\
& Water & 2378 & 1.2787 & 98.5747 & 0.0997 & 0.1248 & 1.7915 & 0.1949 \\
& Urban & 13,871 & 1.3049 & 97.4653 & 0.1456 & 0.2176 & 1.2932 & 0.3486 \\
& Desert & 9643 & 1.1938 & 99.9372 & 0.0253 & 0.0078 & 0.0556 & 0.6228 \\
\hline
\end{tabular}

\section{Discussion}

Like most classic and relevant research, the degree of ecological risk was quantified by an ecological risk index of land use which is only a reflection of the integrated probability of ecological problems. It may have difficulty in reflecting the ecological risk made by some specific sources. However, this paper indeed has some advanced points in the spatial statistical analysis. Results did not only focus on the degree and distribution of the relative eco-risk, but also paid attention to the spatial aggregation. Global and local Moran's I indicated that positive spatial autocorrelations occurred among the ERIs. Since the efforts that the public and government can make to control the eco-risk are limited, spatial statistical analysis can lead the eco-management to pay more attention to these hot areas with " $\mathrm{HH}^{\prime}$ autocorrelation which may cause adverse effects to adjacent areas. Moreover, this paper does not end with the relative risk in the grids of $5 \mathrm{~km} \times 5 \mathrm{~km}$. By semivariance analysis and spatial interpolation, we improve the spatial resolution to the grids of $30 \mathrm{~m} \times 30 \mathrm{~m}$. This resolution can display more detailed spatial distribution of relative ecological risk and provide a more precise basis for the further study.

The ecological risk assessment in Shule River based on the landscape index had the similar results as this research, the landscape risk index presented a positive spatial autocorrelation but weakened during the past 30 years [41]. According to the research of ecological risk appraisal in the course of urbanization in the Hexi corridor, the downstream position has a higher eco-risk than the upstream [42], which coincides with the results in this paper that the eco-risk is lower in the southeast than in the northwest. These consistencies indicate that this research corresponds with the actual landscape 
ecology in the middle reaches of the Heihe River and land use processes can reflect the influence of human activities on landscape ecology. Dynamic ecological risk assessment based on landscape patterns can provide theoretical support and practical guidance for the sustainability of land use.

\section{Conclusions}

This research analyzed the characteristics of the dynamic spatial-temporal changes of ecological risk based on land use data, GIS technical support, spatial autocorrelation analyses, and semivariance analyses. The main conclusions are as follows: (1) the ecological risk of the middle reaches of the Heihe River was generally high, whereas the high ERI values tended to decrease and the low ERI values tended to increase; (2) positive spatial autocorrelations were observed among the ERIs, prominent scale-dependence was observed for the ERI spatial distribution, and the spatial autocorrelations tended to decrease with increases of grain. The hot area with High-High local autocorrelations was mainly located in the north, and the cold area with low-low local autocorrelations was primarily located in the middle corridor plain and the Qilian Mountains. From 2000 to 2014, the hot area of ecological risk decreased, and the cold area increased; and (3) the exponential model for kriging interpolations provided accurate simulations of the spatial patterns of ecological risk in the middle reaches of the Heihe River. From 1986 to 2014, reductions were observed in the low and relatively low ecological risk areas, and increases were observed in the relatively high risk areas. Gaotai, Linze, and Sunanminghua counties had a relatively high level of ecological risk that tended to decrease over time, with Ganzhou and Minle counties exhibiting a middle level of ecological risk, which tended to increase. Shandan County presented a serious polarization, with high ecological risk in the north and low ecological risk observed in the south at the Shandan horse farm.

These results of the study can provide scientific guidance for ecological risk management and ecological construction in the middle reaches of the Heihe River. (1) High risk areas are mainly distributed in the north and concentrated in the Sunanminghua districts and the northern regions of Gaotai and Linze counties. The main types of ecosystems in these areas are desert and low-coverage grassland. Although the intensity of human disturbance is not high, the extremely fragile ecological background leads directly to a higher ecological risk index. In these areas, the risk prevention deserves emphasis and the interference of human activities should be minimized. Ecological planning and construction should be conducted to improve grassland coverage and increase the number of grass species. To improve the regional biodiversity, forest and grass species should be planted in regions of the desert that present suitable conditions because such species can increase the region's ability to resist all types of disturbance and ecological risk; (2) relatively high ecological risk areas were mainly distributed along the periphery of the high ecological risk areas. The desert and low-coverage grassland areas present a landscape pattern with intervals of grassland and desert and obvious patch fragmentation. In these areas, the expansion of oases should be controlled and projects to return cultivated land to forest and grassland should be implemented. In addition, a suitable grazing livestock carrying capacity should be determined in accordance with the quality of grassland; and (3) the middle and low ecological risk areas were mainly distributed in the oases located within the corridor plain and along the edge. The farmland ecosystem is dominant and interspersed with forest, grassland, and desert. Although the current ecological risk is low, the potential for increased ecological risk cannot be ignored. In addition to strict control of oasis expansion, the trend of urban development of farmland should be prevented and protection measures for forest and grassland should be implemented.

Acknowledgments: This research is supported by the National Natural Science Foundation of China (No.41371097).

Author Contributions: As the first author, Jiahui Fan made substantial contributions to the acquisition, analysis and interpretation of the data as well as the drafting and revising of article. Ya Wang, Zhen Zhou, Nanshan You and Jijun Meng contributed equally to this work and they gave important advices for the final version and helped to revise the manuscript.

Conflicts of Interest: The authors declare no conflict of interest. 


\section{References}

1. Turner, B.L.; Kate, R.W.; Meyer, W.B. The earth as transformed by human action in retrospect. Ann. Assoc. Am. Geogr. 1994, 84, 711-715. [CrossRef]

2. Moran, E.F. Global land project: Science plan and implementation strategy (IGBP Report No.53/HDP Report No.19.2005). In Proceedings of the Land Open Science Conference, Morelia, Mexico, 2-5 December 2003; IGBP Secretariat: Stockolm, Sweden, 2005.

3. International Council for Science (ICSU). Future Earth Initial Design (2014-2023); ICSU: Paris, France, 2013.

4. Zhou, T.; Meng, J.J. Research progress in regional ecological risk assessment methods. Chin. J. Ecol. 2009, 28, 762-767.

5. Wang, J.W.; Meng, J.J. Ecological risk assessment and management of floods and droughts in the Li River Basin. Trop. Geol. 2014, 34, 366-373.

6. Tom, B. Ecological risk assessment and quantitative consequence analysis. Hum. Ecol. Risk Assess. 2006, 12, 51-65.

7. Xiao, D.N.; Bu, R.C.; Li, X.Z. Spatial ecology and landscape heterogeneity. Acta Ecol. Sin. 1997, 17, 453-461.

8. Zang, S.Y.; Liang, X.; Zhang, S.C. GIS-based analysis of ecological risk on land-use in Daqing City. J. Nat. Disaster. 2005, 14, 141-145.

9. Xie, H.L. Regional eco-risk analysis of based on landscape structure and spatial statistics. Acta Ecol. Sin. 2008, 28, 5020-5026.

10. Sun, H.B.; Yang, G.S.; Su, W.Z.; Zhu, T.M.; Wan, R.R. Ecological risk assessment. Acta Ecol. Sin. 2010, 30, $5616-5625$.

11. Zhang, X.B.; Shi, P.J.; Luo, J.; Liu, H.L.; Wei, W. The ecological risk assessment of arid inland river basin at the landscape scale: A case study on Shiyang River Basin. J. Nat. Res. 2014, 29, 410-419.

12. Gong, W.F.; Yuan, L.; Dang, Y.F. Study on ecological risk of land use in urbanization watershed based on RS and GIS: A case study of Songhua River watershed in Harbin section. Chin. Agric. Sci. Bull. 2012, 28, 255-261.

13. Zhang, X.F.; Wang, R.S.; Li, Z.G.; Li, F.; Wu, J.S.; Huang, J.L.; Wu, Y.Y. Comprehensive assessment of urban ecological risks: The case of Huaibei City. Acta Ecol. Sin. 2011, 31, 6204-6214.

14. Yang, Y.F.; Sun, X.H.; Wang, B.T. Ecological risking assessment in Shandong province based on landuse landscape structure. Bull. Soil Water Conserv. 2010, 30, 231-235.

15. Liu, X.; Su, W.C.; Wang, Z.; Huang, Y.M.; Deng, J.X. Regional ecological risk assessment of land use in the flooding zone of the Three Gorges Reservoir area based on relative risk model. Acta Sci. Circum. 2012, 32, 248-256.

16. Meng, X.; Ren, Z.Y.; Zhang, C. Study on land use change and ecological risk in Xianyang City. Arid Zone Res. 2012, 29, 137-142.

17. Bayliss, P.; van Dam, R.A.; Bartolo, R.E. Quantitative ecological risk assessment of the Magela Creek Floodplain in Kakadu National Park, Australia: Comparing point source risks from the ranger uranium mine to diffuse landscape-scale risks. Hum. Ecol. Risk Assess. 2012, 18, 115-151. [CrossRef]

18. Wang, W.Q.; Li, T.H. Temporal and spatial variation of ecological risk analysis in Yunnan Province based on land use spatial structure. Acta Sci. Nat. Univ. Pek. 2014, 50, 355-360.

19. Dale, V.H.; Valone, T.J. Ecological principles and guidelines for managing the use of land. Ecol. Appl. 2000, 10, 639-670. [CrossRef]

20. Xie, H.L. Spatial characteristic analysis of land use eco-risk based on landscape structure: A case study in the Xingguo County, Jiangxi Province. Chin. Environ. Sci. 2011, 31, 688-695.

21. Wu, J.G. Landscape Ecology-Pattern, Process, Scale and Class, 2nd ed.; Higher Education Press: Beijing, China, 2007.

22. Liu, J.Y.; Liu, M.L.; Zhuang, D.F. Study on spatial pattern of land-use change in China during 1995-2000. Sci. China 2003, 46, 373-384.

23. USGS. Science for a changing world. Available online: http://earthexplorer.usgs.gov/ (accessed on 2 June 2016).

24. Heihe Planning Data Management Center. Reservoir Data Set of Heihe River Basin; China Cold and Arid Regions Environmental and Engineering Research Institute: Lanzhou, China, 2011.

25. WestDC. Available online: http://westdc.westgis.ac.cn (accessed on 2 June 2016). (In Chinese) 
26. Yaacobi, G.; Ziv, Y.; Michael, L. Effects of interactive scale-dependent variables on beetle diversity patterns in a semi-arid agricultural landscape. Landsc. Ecol. 2007, 22, 687-703. [CrossRef]

27. Qiu, Y.; Yang, L.; Wang, J.; Zhang, Y.; Meng, Q.H.; Zhang, X.G. Grain effect of landscape pattern indices in a gully catchment of Loess Plateau. Chin. J. Appl. Ecol. 2010, 21, 1159-1166.

28. Shen, W.J.; Wu, J.G.; Lin, Y.B.; Ren, H.; Li, Q.F. Effects of changing grain size on landscape pattern analysis. Acta Ecol. Sin. 2003, 23, 2506-2519.

29. Li, X.H.; Zhang, J.Y. Analysis on regional landscape ecological risk based on GIS: A case study along the Lower Reaches of the Weihe River. Arid Zone Res. 2008, 25, 899-903.

30. Jing, Y.P.; Zhang, S.W.; Li, Y. Ecological risk analysis of rural-urban ecotone based on landscape structure. Chin. J. Ecol. 2008, 27, 229-234.

31. Hu, H.B.; Liu, H.Y.; Hao, J.F. The urbanization effects on watershed landscape structure and their ecological risk assessment. Acta Ecol. Sin. 2011, 31, 3432-3440.

32. Xu, X.G.; Lin, H.P.; Fu, Z.Y.; Bu, R.C. Regional ecological risk assessment of wetland in the Huanghe River Delta. Acta Sci. Nat. Univ. Pek. 2001, 37, 111-120.

33. Zeng, H.; Liu, G.J. Analysis of regional ecological risk on landscape structure. Chin. Environ. Sci. 1999, 19, 454-457.

34. Chen, P.; Pan, X.L. Ecological risk analysis of regional landscape in inland river watershed of arid area: A case study of Sangong River Basin in Fukang. Chin. J. Ecol. 2003, 22, 116-120.

35. Liu, M.; Zhao, C.W.; Shi, M.H. Spatial autocorrelation analysis of multi-scale land use change at mountainous areas in Guizhou province. Trans. Chin. Soc. Agric. Eng. 2012, 28, 239-246.

36. Li, X.R.; Li, Y.B.; Han, F.F. Ecological risk assessment of ecological barrier belt in three Gorges Reservoir Areas based on land use. Bull. Soil Water Conserv. 2015, 35, 188-194.

37. Wang, Z.Q. Statistics and Its Application in Ecology; Science Press: Beijing, China, 1999.

38. Liu, A.L.; Wang, P.F.; Ding, Y.Y. Introduction to Statistics; Science Press: Beijing, China, 2012.

39. Meng, J.J. Integrated Physical Geography, 2nd ed.; Peking University Press: Beijing, China, 2011.

40. Tang, G.A.; Yang, X. ArcGIS Geographic Information System Spatial Analysis Experiment Course; Science Press: Beijing, China, 2006.

41. Pan, J.H.; Liu, X. Landscape ecological risk assessment and landscape security pattern optimization in Shule River Basin. Chin. J. Ecol. 2016, 35, 791-799.

42. Sun, X.L.; Fang, C.L. Model and application of ecological risk appraisal in the course of urbanization in arid area. Arid Land Geol. 2006, 29, 668-674.

(C) 2016 by the authors; licensee MDPI, Basel, Switzerland. This article is an open access article distributed under the terms and conditions of the Creative Commons Attribution (CC-BY) license (http://creativecommons.org/licenses/by/4.0/). 